\section{Predictive value of developmental testing in the second year for cognitive development at five years of age}

\author{
Alastair G. Sutcliffe, ' Audrey Soo, \\ Jacqueline Barnes ${ }^{2}$ \\ 'General and Adolescent Paediatrics Unit, \\ Institute of Child Health, University \\ College London, UK \\ 'Institute for the Study of Children, \\ Families and Social Issues, Birkbeck, \\ University of London, UK
}

\section{Abstract}

There is mixed evidence about the predictive validity of the Griffiths mental developmental scales. This study aimed to assess the predictive value of developmental assessments of children in their second year using the Griffiths mental development scales for neuro-developmental status at five years using the Wechsler preschool and primary scale of intelligence, revised (WPPSI-R). In a longitudinal study 253 children were assessed in their second year of life using the Griffiths scales and again at five years using the WPPSI-R. The scores were compared and the predictability of the WPPSI-R outcome on the basis of Griffiths scores was assessed. The WPPSI-R full scale IQ and the performance IQ at age five could be predicted moderately by the Griffiths general quotient (GQ) and by the personal/social scale. The Griffiths GQ was not a significant predictor of verbal IQ at age 5 . The Griffiths performance scale predicted subsequent WPPSI-R performance IQ, and marginally the Full Scale IQ. For the early identification of children at risk for language delay, the Griffiths scales may not be suitable. However, a shortened form would be useful to predict overall cognitive development from the second year to school entry, focussing on the personal-social and performance scales.

\section{Introduction}

It has been known for some time that although the commonly used developmental scales for infants (Bayley mental developmental scales ${ }^{1}$ and the Griffiths scales ${ }^{2}$ ) have some ability to predict skills at a later age, they are not as sensitive as developmental assessments used when children are 5 years or above. This is mainly because of the lack of verbal skills range possessed by toddlers compared to older children, which limits the comparability of the tasks in assessments at the two ages.

Little research has been done to show the predictability of either of the developmental systems. Studies previously done tended to use small numbers of children, ${ }^{3}$ use children who have specific characteristics such as being very premature or having conditions that may affect their development in an unrecognised manner and which could skew the results of the predictability. ${ }^{4-6}$

Some previous studies compared Bayley scales of infant development scores and subsequent WPPSI-R scores. A search of the medical literature revealed only one study, performed in 1977, which compared the Bayley and the Griffiths scales. The sample was small (50) and the infants were from a neonatal follow-up clinic and therefore high-risk for delay in cognitive development. Nevertheless, the potential of the Griffiths scale was suggested by the strong association found between the Griffiths and the Bayley tests.

This study, designed to investigate the development over time of children conceived by assisted reproductive technology (ART) ${ }^{8}$ is also one of the largest to be able to investigate the predictability of neuro-developmental scores in the second year for development in the fifth year of life. The longitudinal study used the Griffiths mental development scales to assess a cohort of children at a mean age of 17 months. These children were reassessed at 54 months of age. ${ }^{9}$ The Griffiths mental development scales have been examined to establish the extent to which they accurately predict children's neuro-developmental progress at 54 months of age using the Wechsler preschool and primary scale of intelligence, Revised (WPPSI-RUK). ${ }^{10}$

The children were either naturally conceived, or from intracytoplasmic sperm injection (ICSI), a type of in vitro fertilisation, but for the purposes of this paper nature of conception is not considered. This report describes the extent to which the earlier cognitive measure can predict subsequent development.

\section{Materials and Methods}

\section{Procedure}

At the original assessment ${ }^{8}$ and at followup, ${ }^{9}$ the children were assessed by a single researcher. In their second year (mean age 17.3 months) all children were assessed by a paediatrician. At the second evaluation (mean age 5.0 years) a trained psychologist assessed the children, unaware of their mode of conception and blind to previous test scores. The
Correspondence: Alastair G. Sutcliffe, General and Adolescent Paediatrics Unit, Institute of Child Health, University College London, WC1N 1EH, London, UK. E-mail: a.sutcliffe@ich.ucl.ac.uk

Key words: development pediatrics, cognitive, children, assessment.

Contribution: AGS and JB contributed to the conception and design of the study; JB contributed to the analysis of data with input from AS. All coauthors contributed to the final manuscript writing.

Acknowledgements: the authors thank all participating families for taking part in this study.

Conflict of interest: the authors report no conflict of interest.

Received for publication: 1 June 2010.

Revision received: 22 July 2010.

Accepted for publication: 2 August 2010.

This work is licensed under a Creative Commons Attribution 3.0 License (by-nc 3.0).

(C) Copyright A.G. Sutcliffe et al., 2010

Licensee PAGEPress, Italy

Pediatric Reports 2010; 2:e15

doi:10.4081/pr.2010.e15

first language of all of the children was English. They were Caucasian, born at term, singleton and with normal birth-weight. Measurements at the two time points were available for 253 children: 165 ICSI conceived children (65.2\%) and 88 naturally conceived children (34.7\%). The sex distribution between the two groups was similar (female 113, male 140). Further details of the original cohort $^{8}$ and the follow-up group ${ }^{9}$ have been previously described.

\section{Measures}

The Griffiths mental development scales ${ }^{2}$ uses a simple ratio transformation, dividing the mental age by chronological age yielding slightly different means and standard deviations for the total index and the scale scores. It yields a general cognitive quotient (GQ, mean 100.2 , s.d. 12.8) and at the 1-2 year age has 5 sub-scales: hearing and speech (mean 99.8 , s.d. 17.8); hand and eye coordination (mean 100.5, s.d. 15.6); personal-social development (mean 100.3, s.d. 16.2); locomotor development (mean 100.4, s.d. 16.3); performance tests (mean 99.8, s.d. 17.2).

The WPPSI- ${ }^{10}$ provides a full scale IQ (mean 100, s.d.15) derived from 10 sub-test scores, grouped into verbal (5 tests) and performance ( 5 tests) and both verbal and performance IQ scores (mean 100, s.d. 10).

\section{Analysis}

Linear regressions were calculated predict- 
Table 1. Summary of regressions of WPPSI-R IQ scores against the Griffiths general quotient score.

\begin{tabular}{lcc} 
WPPSI-R & $\mathbf{R}^{2}$ & $\mathbf{P}$ \\
Verbal IQ & 0.013 & n.s. \\
Performance IQ & 0.088 & 0.002 \\
\hline Full scale IQ & 0.085 & 0.005 \\
\hline
\end{tabular}

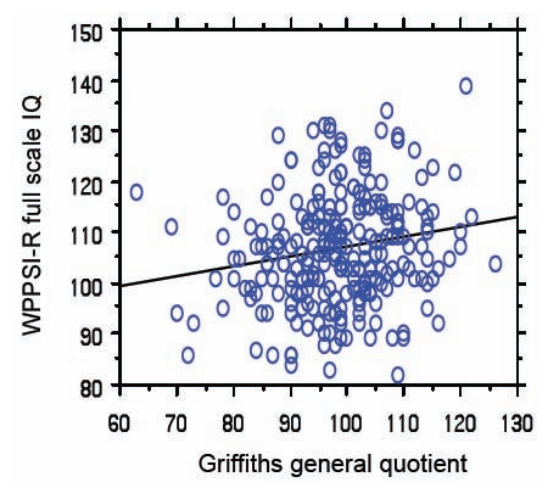

Figure 1. Regression Plot of WPPSI-R full scale IQ and Griffiths general quotient.

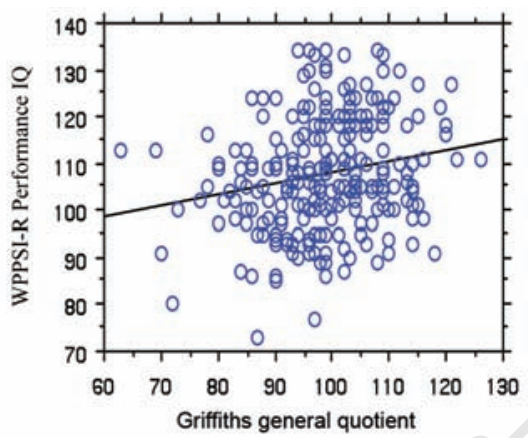

Figure 2. Regression plot of WPPSI-R performance IQ and Griffith general quotient.

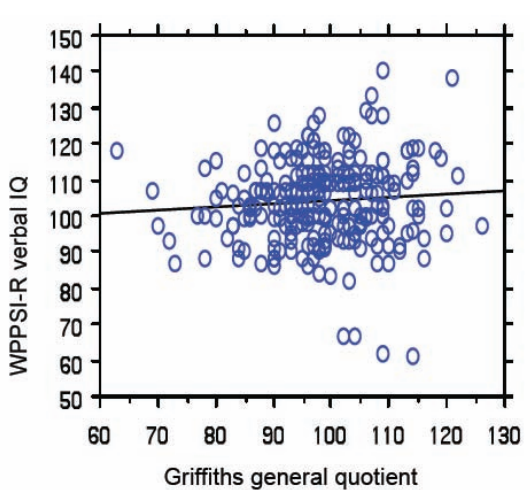

Figure 3. Regression plot of WPPSI-R verbal IQ and Griffith general quotient.

Table 2. Results of ANOVA of Griffiths scales with WPPSI-R full scale IQ.

\begin{tabular}{lrrr} 
Griffiths scale & Mean square & F & P \\
Eye \& hand coordination & 293.41 & 1.66 & 0.199 \\
Hearing and speech & 45.83 & 0.26 & 0.611 \\
\hline Locomotor & 498.67 & 2.83 & 0.095 \\
Performance & 595.88 & 3.38 & 0.068 \\
\hline Personal-social & 1252.35 & 7.10 & 0.009
\end{tabular}

Table 3. Results of ANOVA of Griffiths scales with WPPSI-R performance IQ.

\begin{tabular}{lrrr} 
Griffiths scale & Mean square & F & P \\
Eye \& hand coordination & 52.84 & 0.77 & 0.383 \\
Hearing and speech & 249.16 & 3.62 & 0.059 \\
\hline Locomotor & 4.24 & 0.06 & 0.804 \\
Performance & 477.15 & 6.93 & 0.009 \\
\hline Personal-social & 363.92 & 5.28 & 0.023 \\
\hline
\end{tabular}

ing the WPPSI-R verbal IQ, performance IQ and full scale IQ scores from Griffiths GQ scores and to indicate the variance in WPPSIR IQ explained by the Griffiths GQ. The predictive power of each Griffiths scale was examined using ANOVA.

\section{Results}

The mean Griffiths GQ score (98.39) and mean WPPSI-R scores (FSIQ, 106.01; VIQ 101.03; PIQ 111.21) were in the average range.

\section{Prediction of WPPSI-R IQ scores from Griffiths general quotient}

The Griffiths GQ scores had a weak but statistically significant power to predict subsequent WPPSI-R full-scale IQ and performance IQ (Table 1; Figures 1 and 2). The predictive power of the Griffiths GQ for the WPPSI-R verbal IQ was minimal and not significant (Table 1, Figure 3).

\section{Prediction of WPPSI-R IQ scores from Griffiths scale scores}

Examination of the relationship between the individual Griffiths scales and the WPPSI$\mathrm{R}$ showed that only one scale, personal-social (F 7.10, $\mathrm{P}=0.009$ ) was a significant predictor of the WPPSI-R full scale IQ with marginal prediction from the performance scale (F 3.38, $\mathrm{P}=0.068$ ) and the locomotor scale (F 2.83, $\mathrm{P}=0.095$ ) (Table 2). Two of the Griffiths scales were significant predictors of the WPPSI performance IQ, the performance scale (F 6.93, $\mathrm{P}=0.009$ ) and the personal-social scale (F 5.28, $\mathrm{P}=0.02)$ with marginal prediction from the hearing and speech scale (F 3.62, $\mathrm{P}=0.059$ ) (Table 3).

\section{Discussion}

When trying to predict the subsequent WPPSI-R scores at age 5, the Griffiths scale, completed during toddlerhood at an age when language was only just emerging (17 months), has a significant predictive power for performance IQ and full scale IQs but not the verbal IQ. This suggests that there is less predictive power for this age group in the Griffiths items from the hearing and speech scale that revolve around language-based tasks that are similar to the WPPSI-R verbal IQ score. Those items in the personal/social scale for the second year reflect some verbal skills such as communicating about experiences and these may be more useful than items indicating the extent of vocabulary, which can vary widely during the second year. The Griffiths measure is therefore more likely to be useful as a general indicator of subsequent development, but may not be the most appropriate test if language development is a particular target, for instance of an early intervention or to identify children who may in the future have language delay. It may be more useful for research purposes when mean values for groups are the focus rather than for clinical work focussing on specific children to identify those potentially in need of intervention.

\section{References}

1. Bayley N. Bayley scales of infant development, 2nd edition, 1993. The Psychological Corporation, San Antonio, TX, USA.

2. Griffiths R. The Griffiths mental development scales, 1996 revision. 1996, Henley M., association for research in infant and 
child development, test agency.

3. Conn P. The relations between Griffiths scales assessments in the pre-school period and educational outcomes at 7+ years. Child Care Health Dev 1993;19:275-89.

4. Beail N. A comparative study of profoundly multiply handicapped children's scores on the Bayley and the Griffiths developmental scales. Child Care Health Dev 1985;11:316.

5. Kitchen WH, Rickards AL, Ford GW, et al. Selective improvement in cognitive test scores of extremely low birth weight infants aged between 2 and 5 years. Aust
Paediatr J 1989;25:288-91.

6. Rickards AL, Kitchen WH, Doyle LW, Kelly EA. Correction of developmental and intelligence test scores for premature birth. Aust Paediatr J 1989;25:127-9.

7. Ramsay M, Fitzhardinge PM. A comparative study of two developmental scales: the Bayley and the Griffiths. Early Hum Dev 1977;1:151-1.

8. Sutcliffe AG, Taylor B, Saunders K, et al. Outcome in the second year of life after invitro fertilisation by intracytoplasmic sperm injection: a UK case-control study. Lancet 2001;357:2080-84.
9. Ponjaert-Kristoffersen I, Bonduelle M, Barnes J, et al. International collaborative study of intracytoplasmic sperm injectionconceived, in vitro fertilization-conceived and naturally conceived 5-year-old child outcomes: cognitive and motor assessments. Pediatrics 2005;115:e283-9.

10. Wechsler D. Wechsler Preschool and Primary Scale of Intelligence -Revised (WPPSI-R): Short Form Vocabulary and Block Design, 1989. The Psychological Corporation, Amersham, UK. 